\title{
The Effects of Skin Pressure by Clothing on Whole Gut Transit Time and Amount of Feces
}

\author{
Nana Takasu' ${ }^{1)}$, Sumiko Furuoka1), Naoki Inatsugi' ${ }^{2)}$, \\ Danuta Rutkowska ${ }^{3)}$ and Hiromi Tokura ${ }^{1)}$
}

1) Department of Environmental Health, Nara Women's University

2) Kenseikai Nara Coloproctology Center

3) Department of Physiology, Poznan University of Medical Sciences in Poznan, Poland

\begin{abstract}
The experiment investigated the effects of skin pressure by clothing on whole gut transit time and amount of feces. Comparisons of transit time and amount of feces were taken between 6 young female adults with and without a girdle. The skin pressure applied by a girdle (mean \pm SD) on participant's waist, abdomen and hip region was $16.6 \pm 7.80 \mathrm{mmHg}, 17.1 \pm 4.5 \mathrm{mmHg}$ and $12.6 \pm 5.0 \mathrm{mmHg}$, respectively. The difference of skin pressure with and without a girdle was about $10 \mathrm{mmHg}$. During each experimental period of 4 days with and without a girdle, the whole gut transit time and amount of feces were measured. The whole gut transit time of each day was determined as the time between the oral intake of each day's markers and their first appearance in the stool. The whole gut transit times of the markers taken on the first day were significantly prolonged $(p<0.05)$ and those of the markers taken on the second day tended to be prolonged for participant using a girdle $(p<0.1)$. The whole gut transit time of the markers taken on the third day could not be compared because they were not excreted into the stool. The cumulative increases of feces on the third day and the fourth day were significantly reduced with a girdle $(p<0.05)$. These results indicate that the skin pressure by clothing has an effect on whole gut transit time and the amount of feces. J Physiol Anthropol, 19 (3): 151-156, 2000 http://www.jstage.jst.go.jp/en/
\end{abstract}

Keywords: skin pressure by clothing, whole gut transit time, amount of feces, autonomic nervous system

\section{Introduction}

Constipation is a common problem in our daily life, especially for women. However there is no standard definition of constipation because there are wide variations in normal bowel habits. The slowed intestinal transit time, reduced amount of feces, increased days without defecation and disorders of the anorectal mechanism are the usual abnormalities in patients suffering from constipation. While there are several organic causes, functional disorders are by far the commonest cause of constipation. It is generally known that constipation by functional disorders is caused by less dietary fiber, water intake and exercise, mental stress, irregular life style and no time in defecation. The factors of constipation mentioned above are common to men and women. However, many women are suffering from constipation. One of the reasons for constipation may be due to the tightly fitting underwear for women.

Tokura (1989) found that skin pressure applied by a bodysuit could inhibit the rate of salivary secretion from parotid gland. Okura et al. (2000) found that skin pressure applied by the cuffs could inhibit the rate of salivary secretion and also demonstrated a reduction of amylase concentration in saliva. Tokura and his group suggested that the reduced amount of saliva was induced by suppression of autonomic nervous system activity originating in the saliva secretion center located in the brainstem (Tokura, 1989; Okura et al., 2000). These previous findings suggest that gastric and intestinal secretion may also be suppressed by increased skin pressure due to clothing because these secretions are controlled by the autonomic nervous system (Ganong, 1997). Gastrointestinal motility, which also is under the influence of autonomic nervous control (Ganong, 1997), may be varied for a similar reason as mentioned above.

In this study we have investigated the effect of skin pressure by clothing on whole gut transit time, amount of feces and days without defecation during the experiment, which are closely related with the occurrence of constipation.

\section{Materials and Methods}

Subjects

Six healthy female participants (mean \pm SD, age 21.50 \pm 0.55 years, body weight $54.33 \pm 5.96 \mathrm{~kg}$, height $158.50 \pm$ $4.86 \mathrm{~cm}$ ), who defecate everyday and were not used to wearing a girdle, were studied. All participants were drug free, non-smoker and had been instructed to abstain from 
alcohol for 3 days before the experiment. Experiments were carried out at the participant's follicular phase of the menstrual cycles, excluding menses, because the menstrual cycle may influence the gastrointestinal transit (Wald et al., 1981; Gill et al., 1984).

Each participant gave her informed consent in writing and the experimental protocol was approved by the Ethical Committee of Nara Women's University.

The experiments were performed between October 1998 and December 1998.

\section{Procedure}

The experiment was performed in the climatic chamber where ambient temperature and relative humidity were maintained at $26^{\circ} \mathrm{C}$ and $60 \%$, respectively, throughout the experiment. The light intensity was maintained at $2000 \mathrm{~lx}$ from $0800 \mathrm{~h}$ to $1800 \mathrm{~h}$, at $200 \mathrm{~lx}$ from $1800 \mathrm{~h}$ to $2100 \mathrm{~h}$, at 100 $\mathrm{lx}$ from $2100 \mathrm{~h}$ to $2400 \mathrm{~h}$ and at $0 \mathrm{~lx}$ from $2400 \mathrm{~h}$ to $0800 \mathrm{~h}$.

The experiment consisted of the "no girdle" (NG) and the "girdle" (G) phases and each phase lasted 4 days. During the "NG" phase, the participants wore a shortsleeved knee-length loose dress and knickers. On the other hand, during the " $G$ " phase, the participants wore a shortsleeved knee-length loose dress, knickers and a girdle. The girdle was appropriate for their body size, and was worn from $0800 \mathrm{~h}$ to $2100 \mathrm{~h}$. Skin pressure (mean \pm SD) was 9.3 $\pm 7.3 \mathrm{mmHg}$ and $16.6 \pm 7.80 \mathrm{mmHg}$ at the waist, $6.5 \pm 4.3$ $\mathrm{mmHg}$ and $17.1 \pm 4.5 \mathrm{mmHg}$ at the abdomen and $4.1 \pm 3.0$
$\mathrm{mmHg}$ and $12.6 \pm 5.0 \mathrm{mmHg}$ in the hip region in the "NG" and the "G" phases, respectively. The interval between the "NG" and the "G" phases was approximately at least 1 month apart. The turn of the "NG" / the "G" phase was randomized.

The amount and contents of food and the volume of water taken during the experiment were strictly regulated to be identical between the "NG " and the "G" phases because they may influence the gastrointestinal motility. We also ensured from questionnaire that each participant took approximately the same diet for 3 days prior to the experiment. The amount of locomotor activity in the climatic chamber was almost identical between the "NG" and the "G" phases by a pedometer.

Fig. 1 shows the experimental procedure. The participants spent 4 days mainly sedentary in the chamber. The participants were allowed to listen to music and read magazines, but they were prohibited from taking a nap.

\section{Measurements}

The whole gut transit time was determined by using the radiopaque marker technique. At $0800 \mathrm{~h}$ on the first, second and third day of each phase, every participant took orally one capsule containg 20 radiopaque markers, which were a maximum of $3 \mathrm{~mm}$ in diameter. To calculate the whole gut transit time of the first, second and third day, the participants took different shape markers every day. Over a period of 4 days, all stool portions were collected in

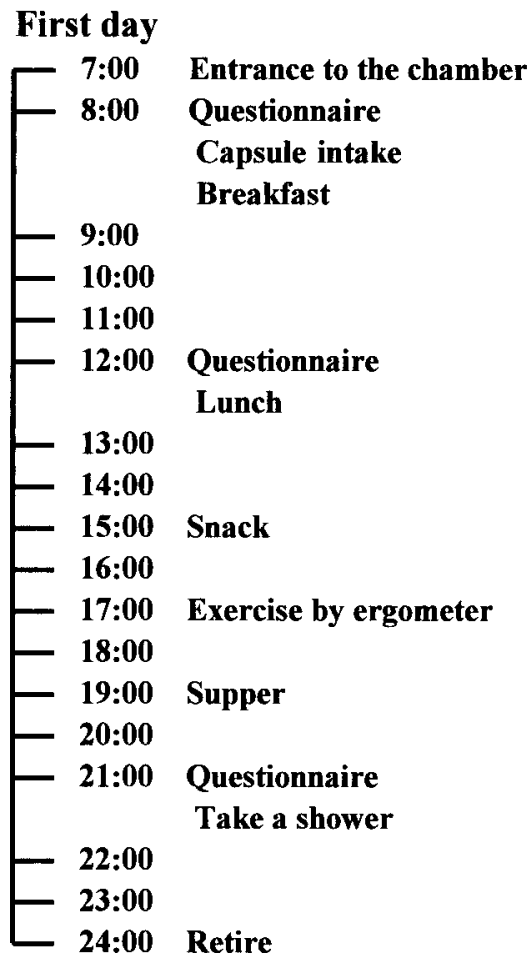

Fig. 1 Experimental schedules.

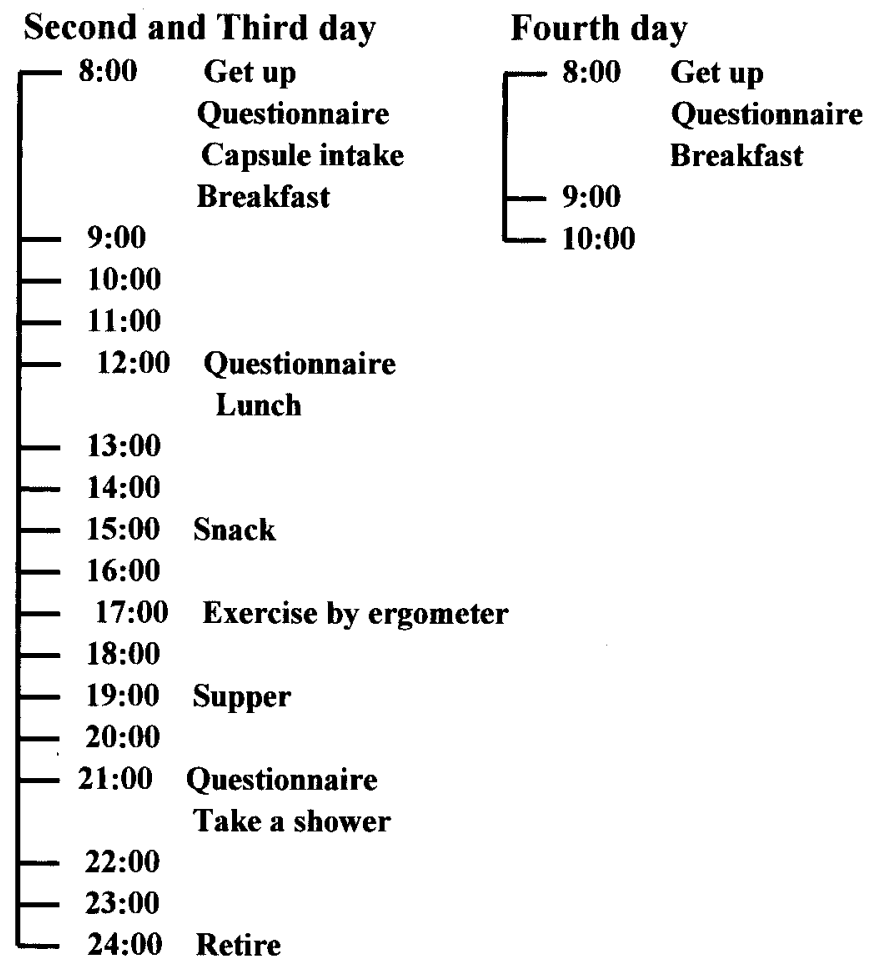


separate plastic bags, weighed with an electronic balance (accuracy 10-mg) and x-rayed. Exact defecation time was noted. The whole gut transit times of each day were determined as the time between the oral intake of each day's markers and their first appearance in the stool. It is assumed that the sooner the appearance of the markers in the feces is, the more active the gastrointestinal motility is.

The sensations of comfort/discomfort and skin pressure with/without a girdle were assessed at 0800h, $1200 \mathrm{~h}$ and $2100 \mathrm{~h}$ during each experimental period by using a questionnaire.

\section{Statistical analysis}

All results were expressed as the mean \pm standard deviation. A paired $t$-test was used for all statistical analysis. A p-value $<0.05$ was considered significant.

\section{Result}

The amount of feces

The cumulative increase of feces is compared between the "NG" and the "G" phases in Fig. 2. There was no significant difference on the first and second day between
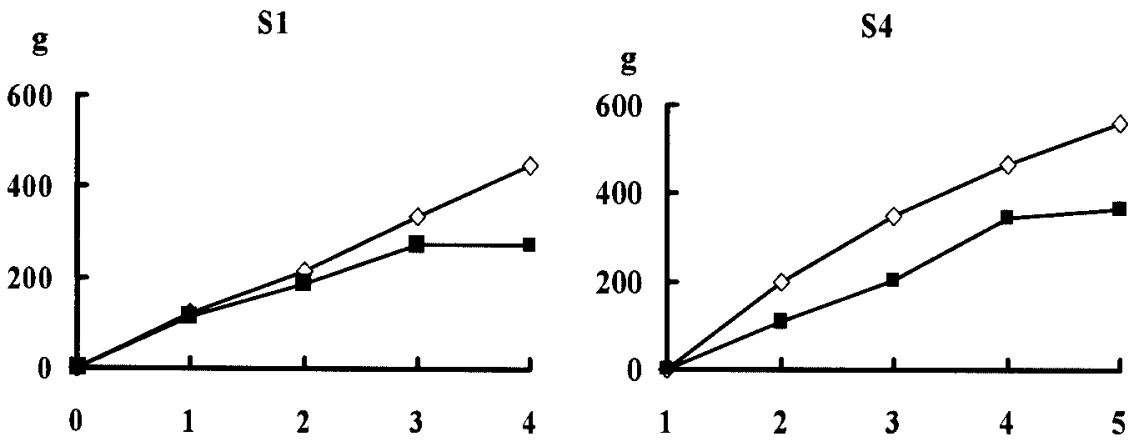

S2
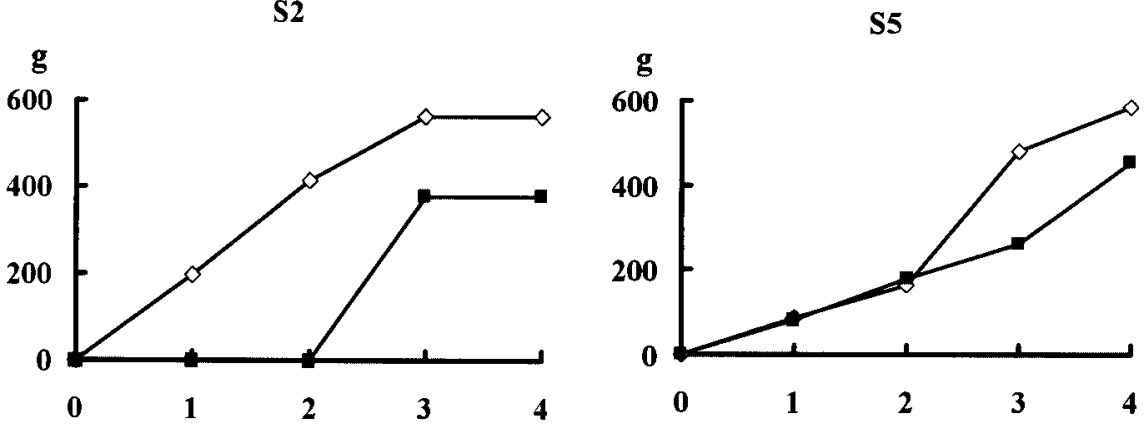

S3

S6
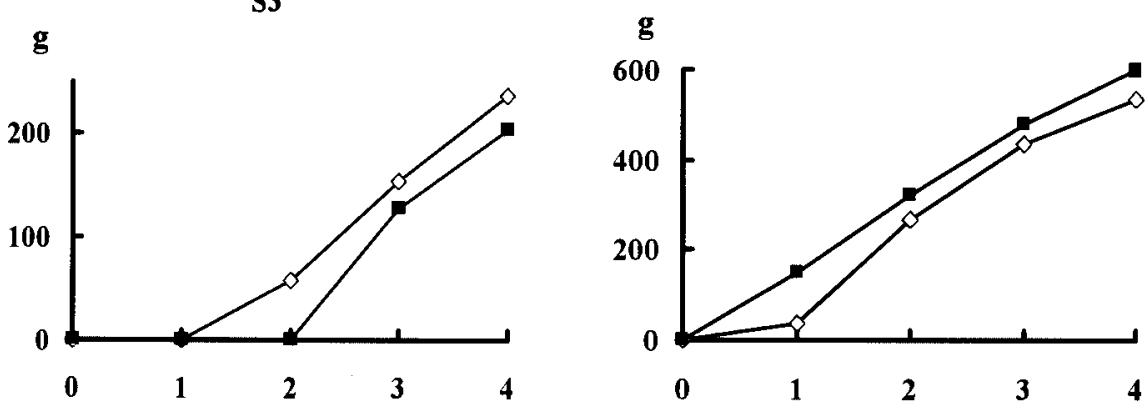

\section{Days}

Fig. 2 Cumulative increase of feces and days without defecation during the "no girdle" ( $\square$ ) and the "girdle" ( $\boldsymbol{\square}$ ) phases in six participants. No increase of feces from day to day was found partly in S1, S2 and S3, indicating that they did not defecate during that period. The final values are the amount of feces cumulated until $1000 \mathrm{~h}$ on the fourth day. 
the "NG" and the "G" phases. However, the cumulative increase of feces significantly decreased in the " $G$ " phase than in the "NG" phase on the third and fourth day $(\mathrm{p}<0.05)$. The values on the third day were $398.48 \pm 145.19 \mathrm{~g}$ and $310.80 \pm 119.90 \mathrm{~g}$ in the "NG" and the "G" phases, respectively. The values on the fourth day were $478.08 \pm$ $132.09 \mathrm{~g}$ and $378.92 \pm 138.66 \mathrm{~g}$ in the "NG" and the "G" phases, respectively. These results indicated that the skin pressure by clothing reduced the amount of feces.

\section{Days without defecation}

Fig. 2 shows the change of cumulative increase of feces between the "NG" and the "G" phases. The flat slope from day to day means that the participants did not defecate during that period. The days without defecation during the whole experimental period was 0 day and 1 day for S1, 1 day and 3 days for S2, 1 day and 2 days for S3, in the "NG" and the "G" phases, respectively, i.e., the days of defecation were less with than without a girdle in three out of six participants. The other three participants, S4, S5, S6, defecated every day during the experiment with/ without a girdle. Thus, the skin pressure due to wearing a girdle tended to increase the days without defecation.

\section{The whole gut transit time of markers}

The whole gut transit times of each day, which are determined as the time between the oral intake of each day's markers and their first appearance in the stool, are compared between the "NG" and the "G" phases in Fig. 3. The whole gut transit times of the markers taken on the first day were significantly prolonged in the " $G$ " phase compared with the "NG" phase $(\mathrm{p}<0.05)$. The mean whole gut transit
A

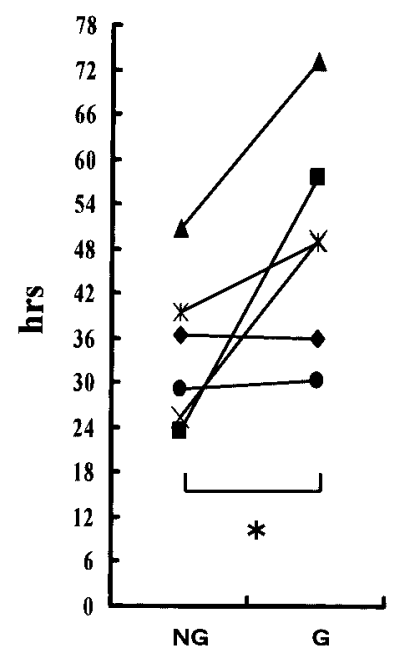

B

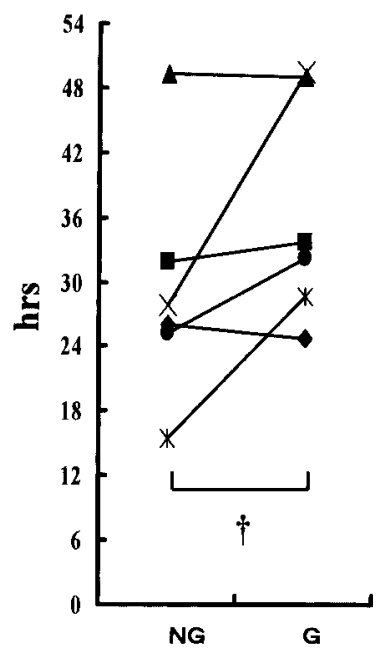

Fig. 3 Whole gut transit times (hrs) of markers taken on the first day's (A) and second day's (B) morning in the "no girdle (NG)" and the "girdle (G)" phases. Each line shows an individual participant. *: $\mathrm{p}<0.05, \uparrow: \mathrm{p}<0.10$. times of the first day's markers were $34 \mathrm{~h} 05 \pm 10 \mathrm{~h} 17 \mathrm{~min}$ in the "NG" phase and 49 h $07 \pm 15$ h 17 min in the "G" phase. The whole gut transit times of the markers taken on the second day tended to be prolonged in the " $\mathrm{G}$ " phase compared with the "NG" phase $(\mathrm{p}<0.10)$. The mean whole gut transit times of the second day's markers were $29 \mathrm{~h} 15$ $\pm 11 \mathrm{~h} 10 \mathrm{~min}$ in the "NG" phase and $36 \mathrm{~h} 17 \pm 10 \mathrm{~h} 30 \mathrm{~min}$ in the "G" phase. The whole gut transit times of the markers taken on the third day could not be compared because they did not appear in the stool before finishing the experiment. These results indicated that the skin pressure with a girdle seemed to prolong the whole gut transit time of the markers.

The sensation of the magnitude of skin pressure and its comfort

The participants felt pressed and uncomfortable in the "G" phase compared with the "NG" phase throughout the experimental period (Fig. 4).
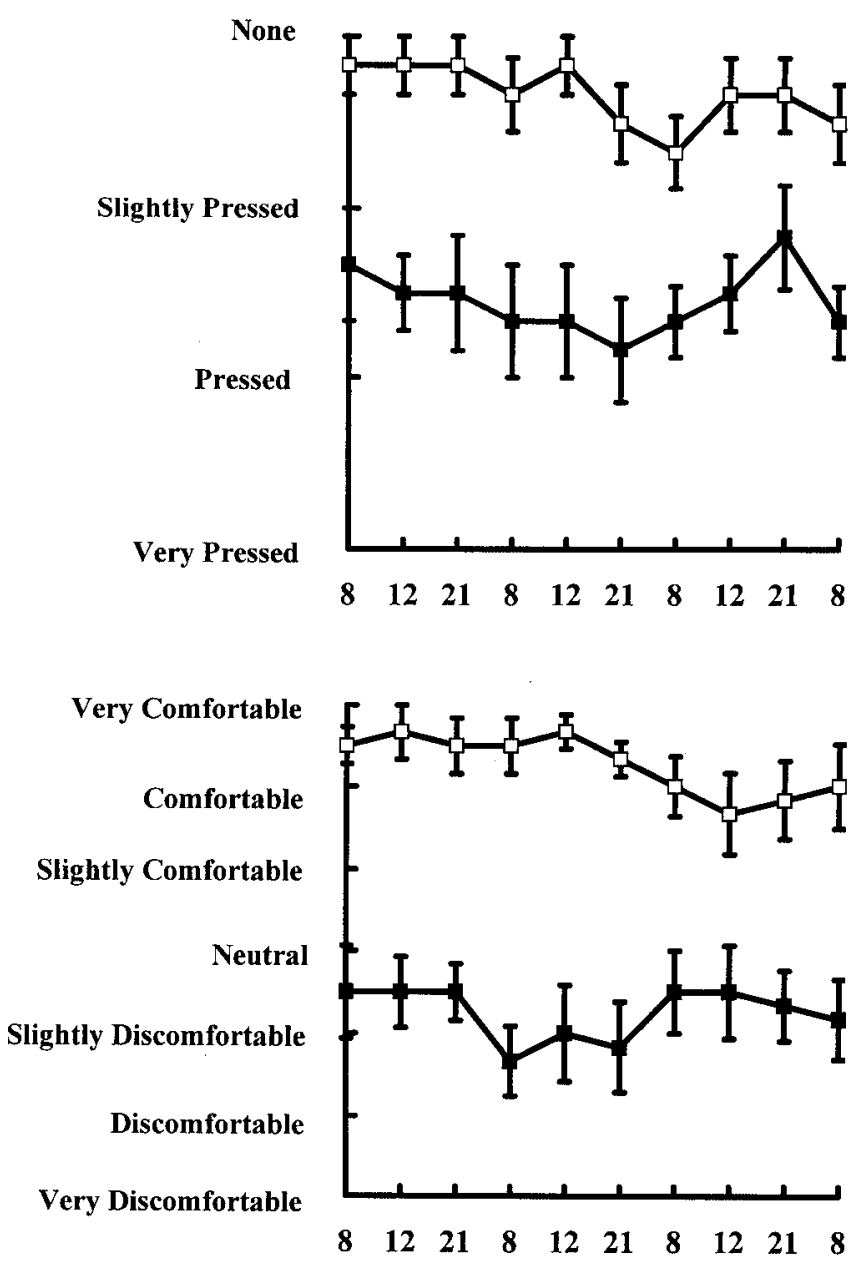

Time of Day (h)

Fig. 4 The questionnaire of the pressed sensation (top) and the comfortable sensation (bottom) in the "no girdle" ( $\square$ ) and the "girdle" ( $\mathbf{\square})$ phases. 


\section{Discussion}

This study showed that the cumulative increase of feces and the days without defecation during the experimental period were reduced and increased, respectively and furthermore the whole gut transit time of the markers was prolonged under the influence of the skin pressure due to wearing a girdle.

The amount of feces and the whole gut transit time of the markers are generally considered to be greatly influenced by the defecation prior to the experiment, the amount of food, dietary fiber, water intake and activity prior to and throughout the experiment (Conen et al., 1992; Ganong, 1997). In the present study, no significant differences in the frequency of defecation and the condition of feces prior to the "G" and the "NG" phases. These factors mentioned above were strictly regulated to be as identical as possible for 3 days prior to and throughout the experiment between the "G " and the "NG" phases. These indicated that the cumulative increase of feces and the whole gut transit time of the markers in this study were not influenced by the factors mentioned above.

Wyman et al. (1978) reported that the amount of feces and the whole gut transit time of the markers changed from day to day. Our results showed that the cumulative increase of feces was significantly less in 5 out of 6 participants and the whole gut transit time of the first day's and second day's markers was longer in 5 out of 6 participants and in 4 out of 6 participants, respectively, in the " $G$ " phase than in the "NG" phase. These observations suggest that the inhibitory tone caused by skin pressure with a girdle on the amount of feces and the whole gut transit time of the markers was beyond their day to day variations.

What physiological mechanisms are responsible for the reduced cumulative increase of feces and the prolonged whole gut transit time of the markers in the " $G$ " phase than in the "NG" phase?

In this study, the skin pressure applied by a girdle prolonged the whole gut transit time of the marker for a mean of 15 hrs in the 1st day's marker, for a mean of $7 \mathrm{hrs}$ in 2nd day's marker. It has been demonstrated that the orocecal transit time was delayed or accelerated for less than 0.5 hrs depending on several factors such as stress under cold, mental irritation and exercise (O'Brien et al., 1987; Keeling et al., 1990). The stress under cold, mental irritation and exercise was different from the stress of this study. However, we predicted that skin pressure by a girdle has a small effect as mentioned above, on the oro-cecal transit time and mainly suppressed the motility of the big intestine, resulting in the longer stay of feces in the big intestine.

Wyman et al. (1978) reported that wet fecal weight and the whole gut transit time of the markers were negatively correlated, but dry fecal weight and the whole gut transit time of the markers were not correlated. This indicates that the longer the whole gut transit time is, the lighter the wet fecal weight is, and its main reason was the reduced volume of water contained in "wet feces". The reabsorbtion of water from the feces might have been greater in the "G" phases of our present experiments because the feces remained longer in the large intestine, resulting in a decrease in their total amount (Ganong, 1997). The whole gut transit time slowed by the skin pressure due to wearing a girdle made daily defecation irregular, resulting in a decrease in the cumulative increase of feces excreted during the experiment. No defecation day could delay gastric emptying (Tjeerdsma et al., 1993), resulting in a prolongation of whole gut transit time and a decrease in the cumulative increase of feces excreted during the experiment.

Furthermore, Tokura and his group found that increased skin pressure inhibited salivary secretion and reduced salivary amylase concentration. These findings were accompanied by a lengthening of time required for digestion of starch (Tokura, 1989; Okura et al., 2000). Digestive juices may have been secreted more slowly and been more diluted by the skin pressure in our present study. Meals remained longer in the stomach under the inhibition of acid-pepsin secretion with cimetidine (Kerrigan et al., 1991). The delayed appearance of the markers excreted in the stool and the reduced cumulative increase of feces in the "G" phases of our experiments may be explained by the physiological changes mentioned above.

Increased activation of the sympathetic nervous system could suppress the motility of the stomach and the small/large intestines and increased activation of the parasympathetic nervous system could enhance the motility of the stomach and small/large intestines (Ganong, 1997). Sugimoto (1991) reported that skin pressure applied by a girdle during daytime enhanced urinary norepinephrine. On the other hand, the different value of skin pressure may cause different response to norepinephrine. Lower skin pressure by the clothing could inhibit the activity of sympathetic and parasympathetic nervous systems (personal communication with $\mathrm{S}$. Watanuki). It remains to be known how the sympathetic and parasympathetic nervous systems were relevant to our present findings.

It is concluded that the cumulative increase of feces was reduced and the days without defecation during the experimental period increased and the whole gut transit time of the markers was prolonged by the skin pressure applied by a girdle. The skin pressure due to wearing a girdle may be one of the factors causing constipation.

Acknowledgement. The authors sincerely thank Dr. Jim Waterhouse in Liverpool, United Kingdom and Dr. Yoshiaki Sone in Osaka City Univ. for their critical reading and editorial assistance. 


\section{References}

Coenen C, Wegener M, Wedmann B, Schmidt G, Hoffmann $S$ (1992) Does physical exercise influence bowel transit time in healthy young men? Am J Gastroenterol 87 (3): 292-295

Ganong WF (1997) Review of medical physiology. APPLETON\&LANG, Stamford, CT, 210-216, 448-479

Gill RC, Murphy PD, Hooper HR, Bowes KL, Kingma YJ (1987) Effect of the menstrual cycle on gastric emptying. Digestion 36: 168-174

Keeling WF, Harris A, Martin BJ (1990) Orocecal transit during mild exercise in women. J Appl Physiol 68 (4): 1350-1353

Kerrigan DD, Mangnall YF, Read NW, Johnson AG (1991) Influence of acid-pepsin secretion on gastric emptying of solids in humans: studies with cimetidine. Gut 32: 1295-1297

O'Brien JD, Thompson DG, Burnham WR, Holly J, Walker E (1987) Action of centrally mediated autonomic stimulation on human upper gastrointestinal transit: a comparative study of two stimuli. Gut 28: 960-969

Okura K, Midorikawa-Turutani T, Tokura H (2000) Effects of the pressure applied by the cuffs on resting salivary secretion. J Physiol Anthropol 19: 107-111
Sugimoto H (1991) Compression of body by clothingIncrease in urinary norepinephrine excretion caused by foundation garments. Jpn J Hyg 46 (2): 709-714 (Japanese with English abstract)

Tjeerdsma HC, Smout AJPM, Akkermans LMA (1993) Voluntary suppression of defecation delays gastric emptying. Dig Dis Sci 38 (5): 832-836

Tokura H (1989) Physiological significance of clothing and human health. In Tokura $\mathrm{H}$ ed. Proceeding of International Symposium of Clothing Comfort Studies in Mt. Fuji. The Japan Research Association for Textile End-Uses Publishing, Osaka, 203-222

Wald A, Van thiel DH, Hoechstetter L, Gavaler JS, Egler KM, Verm R, Scott L, Lester R (1981) Gastrointestinal transit: the effect of the menstrual cycle. Gastroenterology 80: 1497-1500

Wyman JB, Heaton KW, Manning AP, Wicks AC (1978) Variability of colonic function in healthy subjects. Gut 19: $146-150$

Received: January 21, 2000

Accepted: March 21, 2000

Correspondence to: Hiromi Tokura, Department of Environmental Health, Nara Women's University, Nara 630-8506, Japan

e-mail: tokura@cc.nara-wu.ac.jp 